\title{
Ergonomical Methods of Evaluating Repeated Shocks and Vibrations on High Speed Ships (1st Report)
}

\author{
by Hiroshi KANDA*, Yoshio MURAYAMA*, \\ Masato TANAKA** and Kiyoshi SUZUKI**
}

高速艇における繰返し衝撃, 振動の人間工学的評価法一 I

抄

録

乘心地指数, 振動感覚量, 輈柱の傷害にかかわる力学的反応指数といわれる三つの指標を使用して, 高速 艇の典型的な衝撃性振動を対象とする，人閒の耐性からみた多角的評価法を確立することを目的としている。 この方法の特徵注，衝撃または振動に対応する人間の周波数特性からなるウェイティング・ネットワークを 使用することに着目したことである。検討の結果, この方法は人間耐性からの評価にとって優れた手法であ ることが認められる。

\begin{abstract}
The study intends to establish many-sided evaluation method based on human tolerance for typical impulsive vibration on high speed ships by the use of three indices named vibration ride quality index, vibration sensibility magnitude and dynamic response index related to spinal injury. The method is featured by employment of weighting network composed of frequency characteristics of human response to shock and vibration. Results of the study testifies that this method is excellent for evaluation of repeated shocks and vibration based on human tolerance.
\end{abstract}

\section{Introduction}

Frequent occurence of low back pain among the crew of high speed ships becomes a serious problem in recent years.

G. A. Allen is of opinion that spinal injuries closely related to the low back pains are resulted from repeated shocks and proposed a specification giving guidance on tolerance of repeated shocks to ISO $^{(1)}$. The proposal has been examined by ISO and is giving a strong impetus to researchers in this field. However, very little substantiation by actual field studies is available to prove that the low back pains are caused by the load due to repeated shocks exerting on the spinal column.

On the other hand consideration should be given to the fact that the low back pains are also caused by accumulation of musclar fatigue. This condition is incurred by reflective strain of the muscle for stabilizing posture against vibrations of following two categories: a) Vibrations in frequencies below $1 \mathrm{~Hz}$, that is, ship's oscillatory motions including heaving, rolling and pitching. b) Repeated shocks and vibrations in frequency range from 1 to $80 \mathrm{~Hz}$.

The authors have first obtained vibration ride quality index, vibration sensibility magnitude and dynamic response index related to spinal injury on the basis of acceleration waves of repeated shocks and vibrations on high speed ships. Then they obtained a clue to many-sided evaluation as viewed from the human tolerance, which is presented here as the first report.

* Member: Maritime Labour Research Institute

** Member: Research Institute of Marine Engineering 


\section{Analysis and evaluation method of acceleration waves}

2. 1 Block diagram for analysis of acceleration waves

A method is strongly desired to find easily the vibration ride quality index, the vibration sensibility magnitude and the dynamic response index related to spinal injury from acceleration waves registered on a data-recorder. The analysis presented was carried out by employing a weighting network obtained from frequency characteristics of human response to shocks and vibrations. Evaluation was made for the acceleration of shocks and vibrations in vertical direction.

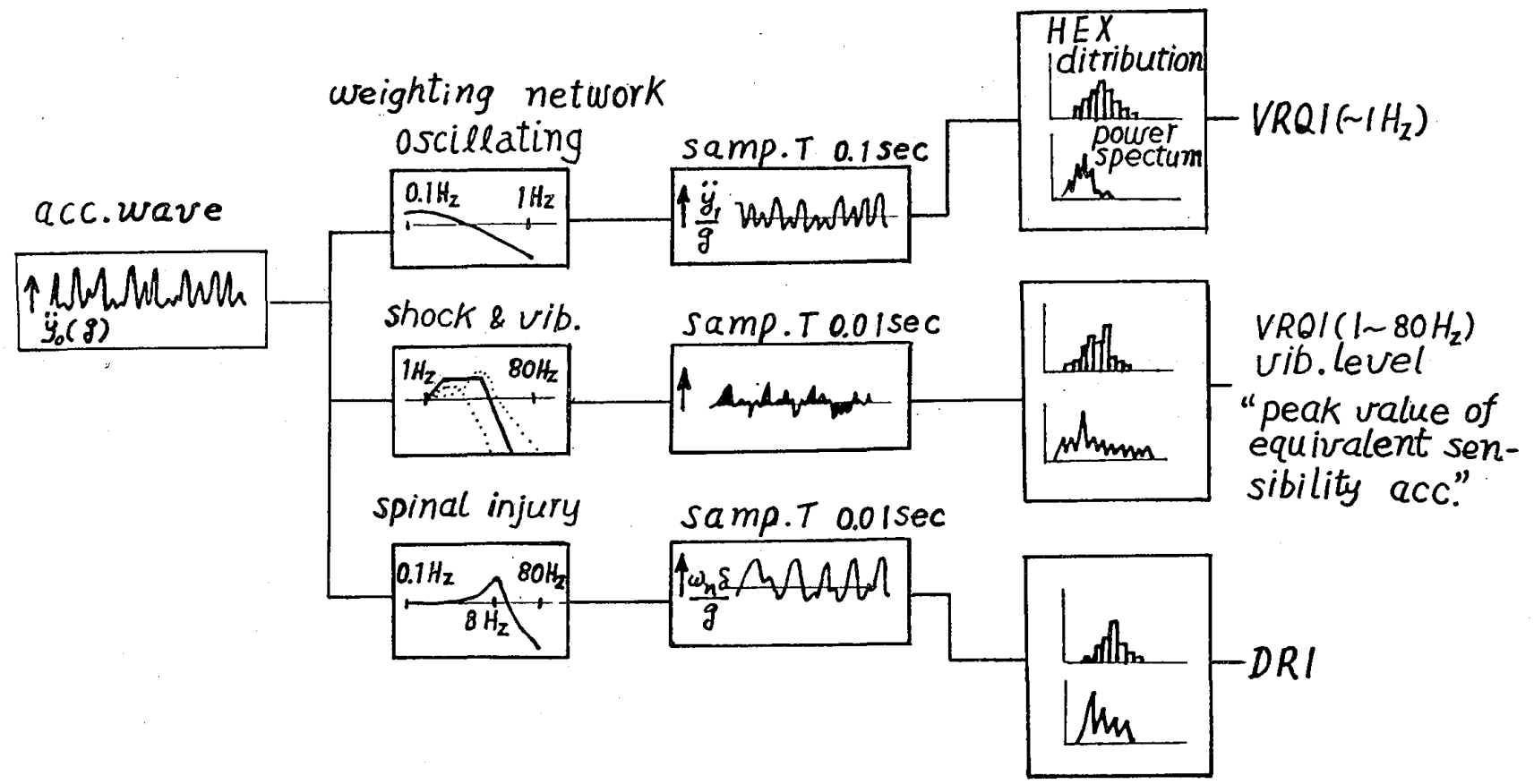

Fig. 1 Block diagram for analysis of acceleration waves

The block diagram is shown in Fig. 1. The diagram gives procedure to obtain. appropriate evaluation index and vibration sensibility magnitude after actual acceleration waves passed the weighting network and its weighted signal was analyzed as input of real time digital analyzing system.

The weighting network is to be used for evaluation of: a) vibrations in the frequency range from 0.1 to $1 \mathrm{~Hz}$ called as ship's oscillatory motions, b) vibration. in the frequency range from 1 to $80 \mathrm{~Hz}$ acting on human body called as shocks, or vibration sensibility; and c) dynamic response of the spinal column in relation to incidence of the low back pain.

Sampling time should be selected carefully, especially in the case of impulsive vibration. As shown in Fig. 1, the sampling time is 0.1 sec. for acceleration wave in the frequency range from 0.1 to 1 $\mathrm{Hz}$, and 0.01 sec. for 1 to $80 \mathrm{~Hz}$.

The sampling time was determined by the check of oscillograph to reproduce the original wave patterns as exactly as possible. Half magnitude extreme value distribution (HEX distribution) and power spectrum can be obtained instantaneously by means of the real time digital analyzing system.

2. 2 Weighting network for evaluation index or vibration sensibility magnitude

2. 2. 1 Vibration Ride Quality Index

- VRQI $(\sim 1 \mathrm{~Hz})$ and VRQI $(1 \sim 80 \mathrm{~Hz})-$

Vibration ride quality index is an index to ride quality on a vehicle proposed by P. R. Payne and his cooperators ${ }^{(2)}$.

In the present paper the vibration ride quality index is classified into two categories: one is the vibration in the frequency range below $1 \mathrm{~Hz}$ and the other is the vibration in a frequency 
range from 1 to $80 \mathrm{~Hz}$. They are hereinafter referred to as VRQI $(\sim 1 \mathrm{~Hz})$ and VRQI (1 $80 \mathrm{~Hz})$ respectively. VRQI $(\sim 1 \mathrm{~Hz})$ is an evaluation index viewed from degree of difficulty in ordinary tasks or from motion sickness incidence caused by ship's oscillatory motion. VRQI $(1 \sim 80 \mathrm{~Hz})$ is an evaluation index of the vibration in a frequency range from 1 to $80 \mathrm{~Hz}$ on the basis of tolerable limit of spinal, viscerals and body.

These VRQIs are determined by four dynamic models of human body: low frequency, spinal, viscerals and body. (*Appendix) To be more precisely they are evaluated by the maximum rms value of acceleration of the masses in these four models. The proposal sets the limit values for "tolerable limit" as 0.2 for an exposure less than one hour and 0.1 for longer term. The limit values are also set for "severe" as 0.5 for exposure less than one hour and 0.2 for longer term.

In the study the authors tried to investigate synthetically after evaluating VRQI on each four dynamic models.

The weighting factors for VRQI $(\sim 1 \mathrm{~Hz})$ were obtained from the following equation by applying vibration theory on sinusoidal vibration.

$$
\ddot{Y}_{0} / \ddot{Y}_{1}=\sqrt{\frac{\left[2 \mathrm{c}\left(\omega / \omega_{n}\right)\right]^{2}+\left[1-\left(\omega / \omega_{n}\right)^{2}\right]^{2}}{1+\left[2 \bar{c}\left(\omega / \omega_{n}\right)\right]^{2}}}
$$

where $\overline{\mathrm{c}}=1.0, \omega_{n}=1.571 \mathrm{rad} / \mathrm{sec}$

$\ddot{Y}_{0}$ : amplitude of acceleration on the input side

$\ddot{Y}_{1}$ : amplitude of acceleration of mass $m_{1}$ in the "low frequency" model

Fig. 2 provides the weighting factors of VRQI $(\sim 1 \mathrm{~Hz})$.

The weighting factors for VRQI $(1 \sim 80 \mathrm{~Hz})$ are obtained each for spinal, viscerals and body. During investigation it was found that in sinusoidal vibration "severe, less than one hour" of VRQI is related to one hour exposure limit specified in ISO $2631^{(3)}$ as shown in Fig. 3. The left ordinate in Fig. 3 represents the acceleration (rms) and the right ordinate represents the weighting factors for three dynamic models. It is found that a given ISO curve roughly corresponds with the critical courve composed of the response of three models for VRQI (1 $80 \mathrm{~Hz})$. In consequence, VRQI $(1 \sim 80 \mathrm{~Hz})$ can be obteined by doubling the rms value of acceleration waves passed the weighting network for equivalent sensibility of vertical sinusoidal vibration in ISO 2631 .

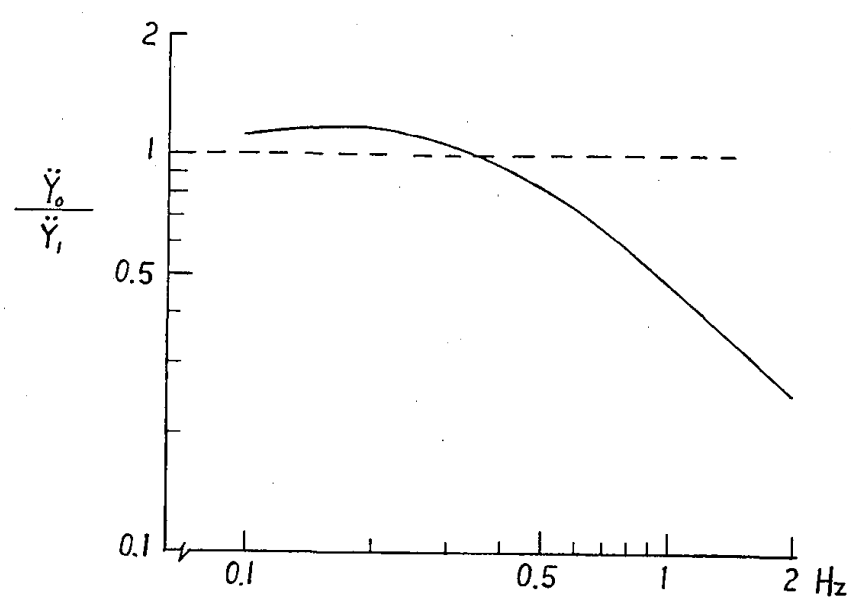

Fig. 2 Weighting factor for VRQI $(\sim 1 \mathrm{~Hz})$

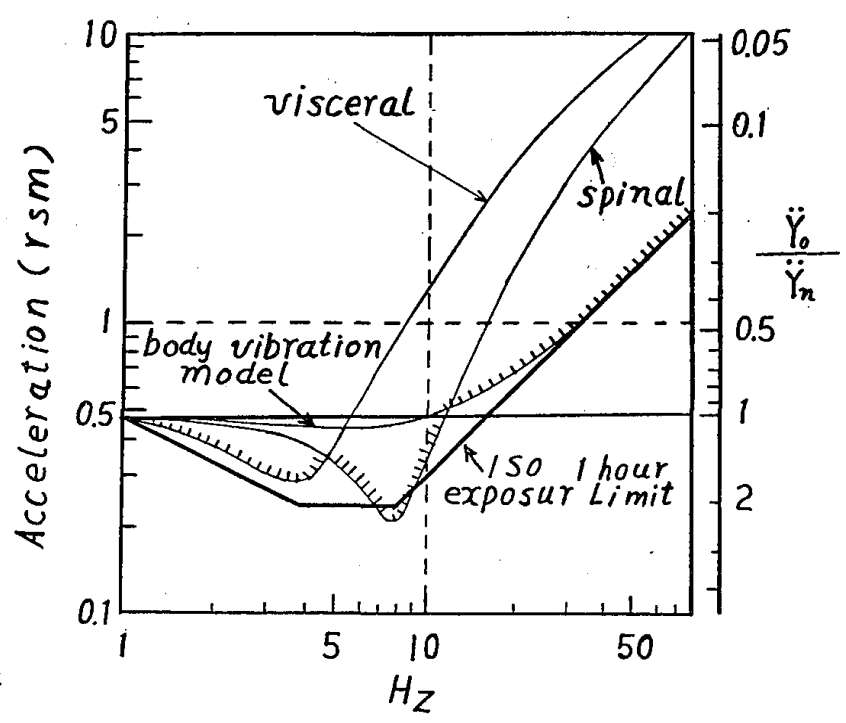

Fig. 3 Relationship between three model responses of "Sever, less than one hour" and ISO 2631 one hour exposure limit 
2. 2. 2 Vibration level (VL), Peak value of equivalent sensibility acceleration (ESA)

VL can be odtained by the use of vibration level meter defined by Japanese lndustrial Standards (JIS). In the vibration level meter is incorporated the weighting network for equivalent sensibility specified in ISO. Accordingly, VL is the vibration magnitude indicated on the meter representing the rms value of the acceleration waves passed the weighting network. VL is expressed in $\mathrm{dB}$ and is defined in ISO as follows:

$$
\begin{aligned}
& d B=20 \log _{10} a / a_{0} \\
& \text { where } a_{0}=10^{-5} \mathrm{~m} / \mathrm{sec}^{2}
\end{aligned}
$$

Therefore $2.0 \mathrm{~m} / \mathrm{sec}^{2}, 1.0 \mathrm{~m} / \mathrm{sec}^{2}, 0.5 \mathrm{~m} / \mathrm{sec}^{2}, 0.2 \mathrm{~m} / \mathrm{sec}^{2}$ and $0.1 \mathrm{~m} / \mathrm{sec}^{2}$ correspond to $106 \mathrm{~dB}$, $100 \mathrm{~dB}, 94 \mathrm{~dB}, 86 \mathrm{~dB}$ and $80 \mathrm{~dB}$ respectively. In the study the vibration level was obtained by the following process. Firstly the acceleration waves was weighted by using the weighting network for equivalent sensibility. Then the rms value of thus weighted acceleration waves was obtained by using the real time digital analyzing system, the result of which is expressed in g-unit. In the third stage, the result was converted into $d B$, which was considered equivalent to VL.

H. Kanda states in his study on human sensibility evaluation to ship vibration ${ }^{(4)}$ that VL is the most suitable vibration magnitude for the vibration sensibility rating. He insists further that the judgement categories of "indifferent", "somewhat", "considerably" and "very" which evaluate the vibration severity on the basis of human sensibility are cnrresponding to VL of $77 \mathrm{~dB}, 83$ $\mathrm{dB}, 89 \mathrm{~dB}$ and $95 \mathrm{~dB}$ respectively. These evaluation criteria, however, were obtained by semantic differential method for the accommodation of large commercial ships.

The peak value of ESA, newly designated in the present paper, means the peak value of the acceleration waves obtained by passing the weighting network for equivalent sensibility specified in ISO. The peak value is the maximum value during a given period. The human sensibility to the acceleration of vertical vibration reaches a maximum for frequencies between $4 \mathrm{~Hz}$ and 8 $\mathrm{Hz}$. It is useful for evaluation of a vibration magnitude based on human sensibility to express the acceleration of over all vibration for the frequency range from 1 to $80 \mathrm{~Hz}$ in equivalent to the sensibility for the vibration in frequency range from 4 to $8 \mathrm{~Hz}$. Especially it is indispensable for evaluation of shock sensibility on high speed ships.

2. 2. 3 Dynamic Response Index (DRI)

This index was proposed by P. R. Payne and his cooperators and has relation to the spinal injury caused by shocks. The fact that occurrence rate of the spinal injury can be evaluated by DRI was testified by the dynamic model tests ${ }^{(5)}$ carried out to establish a design criterion for a system of upward ejection of the seat with the pilot in an aircraft.

DRT is expressed as $\omega_{n}^{2} \delta \mathrm{max} / \mathrm{g}$, in which $\delta$ is displacement of the mass $\mathrm{m}_{2}$ in a spinal model. (* Appendix) If the concept of DRI is accepted, the spinal injury is regarded as being caused by repeated load, which, in consequence, supports the fact that the spinal injury can also be caused by considerable slow loading such as those in carrying heavy loads. Since the frequency range used in the weighting network described later on was not clear in the documents, the frequency range covered in the study between $0.1 \mathrm{~Hz}$ and $80 \mathrm{~Hz}$ under the reasons as aforementioned.

The weighting factor for DRI can be obtained by the following formula, results of which are shown in Fig. 4.

$$
\frac{\text { Peak input "g" }}{\text { DRI } \cdot g}=\frac{\ddot{Y}_{0}}{\omega_{n}^{2} \delta \max }=\sqrt{\left[2 \overline{\left.\mathrm{c}\left(\omega / \omega_{n}\right)\right]^{2}+\left[1-\left(\omega / \omega_{n}\right)^{2}\right]^{2}}\right.}
$$




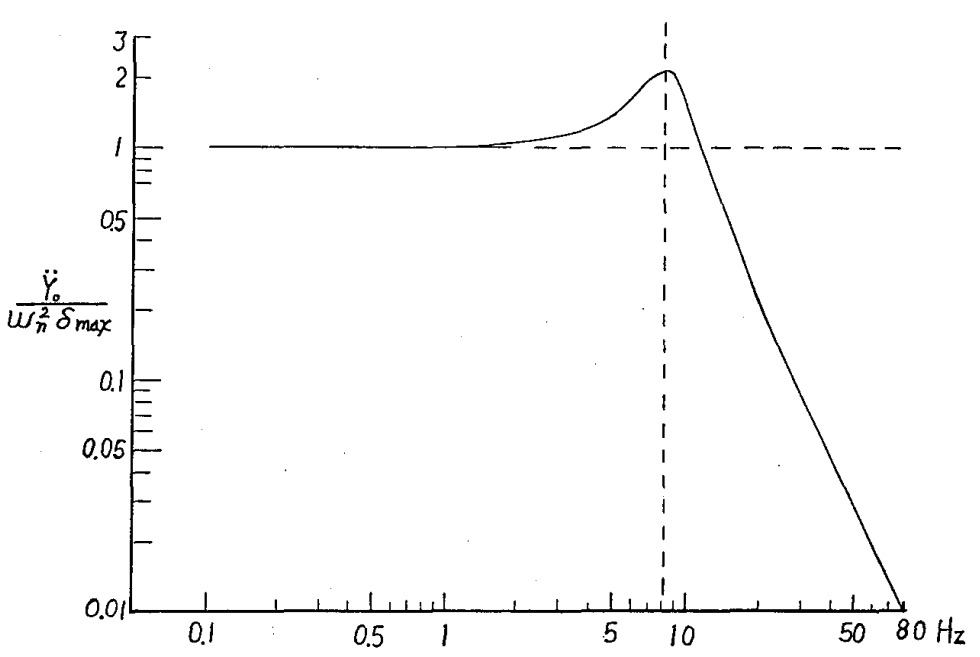

Fig. 4 Weighting factor for DRI
Where $\overline{\mathrm{c}}=0.224, \omega_{n}=52.9 \mathrm{rad} / \mathrm{sec}$ According to the tentative limit of DRI proposed by G. R. Allen, DRIs for condition that occurence rate of such spinal injury as requiring 100 days for recovery is five percent will be approximately $8,6.5,5.5$ and 5 for numbers of repeated shock a day of $10,100,1000$ and 10000 respectively. Though the tentative limit will further be investigated and modified, it is highly expected for its future usefulness.

2. 3 Analyzing period and crest factor

Analyzing period of acceleration waves is limited by sweeping period which depends upon the data size of the real time digital analyzing system and the sampling time. Analysis of vibrations in the frequency range below $1 \mathrm{~Hz}$ requires, as mentioned before, $0.1 \mathrm{sec}$. for the sampling time. In consequence, the sweeping period of this analyzing system will be approximately 1.00sec. under the limitation that the maximum data size is 1024. On the other hand, the analysis of impulsive vibration in the frequency range $1 \mathrm{~Hz}$ to $80 \mathrm{~Hz}$ requires $0.01 \mathrm{sec}$. for the sampling time and the sweeping period will be approximately $10 \mathrm{sec}$.

The analyzing period necessary for evaluation should, however, be determined by considering the following conditions. One is that the vibration of acceleration waves excited by ocean waves are random, and since the peak value is the maximum deviation of that quantity from the mean value during a given interval, the longer analyzing period is in higher probability of obtaining larger peak value. Consequently, large peak value cannot be obtained by single analysis of the sweeping period of $10 \mathrm{sec}$. The other is that crest factor (CF), the ratio of a peak value to rms value, is attracting attention within ISO members. The proposed amendment to ISO $2631^{(6)}$ states that this Standard is applicable to the crest factor below six and proposes that the acceleration waves should be weighted by the weighting network for equivalent sensibility and exposure periods of at least one minute are required. This also means, in the case of higher crest factors than six, other evaluation method for repeated shocks than this Standard is required, and the analyzing period in the study of not less than one minute is desired.

On the basis of consideration of aforementioned conditions, it was decided that evaluation by means of appropriate evaluation index and vibration sensibility magnitude should be made for the analyzing period of $100 \mathrm{sec}$. Accordingly, the analysis for the vibration including impulsive vibration in the frequency range from 1 to $80 \mathrm{~Hz}$ was repeated successively 10 times with sweeping period of 10 sec. The rms value of the acceleration waves within the aggregated total period of 100 sec. can be obtained approximately by calculation described later on. The crest factor can be obtained by dividing the maximum peak value during the analyzing period of 100 sec. by the rms value within totalized period of $100 \mathrm{sec}$. Evaluation by DRI was made employing the peak value of DRI showing the most severe conditions during the analyzing period of $100 \mathrm{sec}$.

\section{Results and consideration}

Prior to explanation of analyzing example by the real time digital analilyzing system, an example of typical acceleration time histories for high speed ships is shown in Fig. 5. The example shows the 


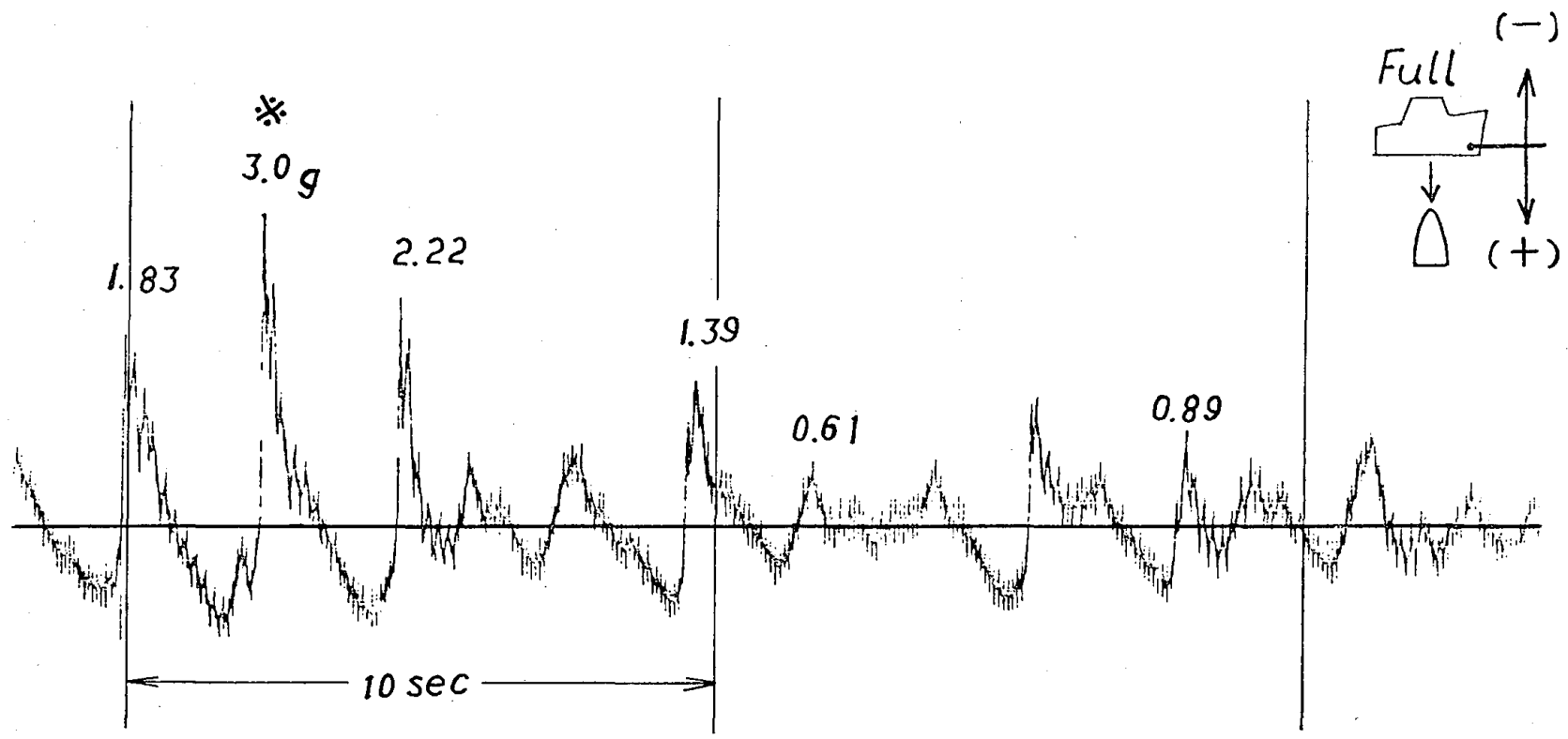

Fig. 5 Typical acceleration-time histories for high speed ship

results obtaned under such extreme severe test conditions as rough sea, full speed, head sea and measuring at fore part of accommodation. The test ship was 65 tons of gross tonnage and $21 \mathrm{~m}$ of overall length, and the trial speed was 24 knots. As to sea conditions, wind speed was $6 \mathrm{~m} / \mathrm{sec}$, wave height $2 \mathrm{~m}$ and wave length $15 \mathrm{~m}$ to $30 \mathrm{~m}$. The acceleration appearing in Fig. 5 presents sawtooth waves or symmetrical triangular waves and may be regarded as a typical impulsive vibration. The ship hull jumps at the wave crest and drops upon the water near the wave trough, thus resulting in exerting repeat of strong landing shocks upon the ship hull. It is noticed in Fig. 5 that severe shock excitations such as the peak value during this period reaches as large as $3 \mathrm{~g}$ exert on the foreward hull.

The period including the most severe impulsive vibration in Fig. 5 was taken up as an object and analyzed according to the block diagram shown in Fig. 1. Examples of the results of analysis will be given to help the explanation. Position of the peak value in this period is marked with $\%$ on the acceleration wave concerned.

Fig. 6 shows an example of analysis of acceleration waves passing the weighting network for VRQI $(\sim 1 \mathrm{~Hz})$. The peak value during the analyzing period of $100 \mathrm{sec}$. is $1.1 \mathrm{~g}$ and the rms value is $0.35 \mathrm{~g}$.

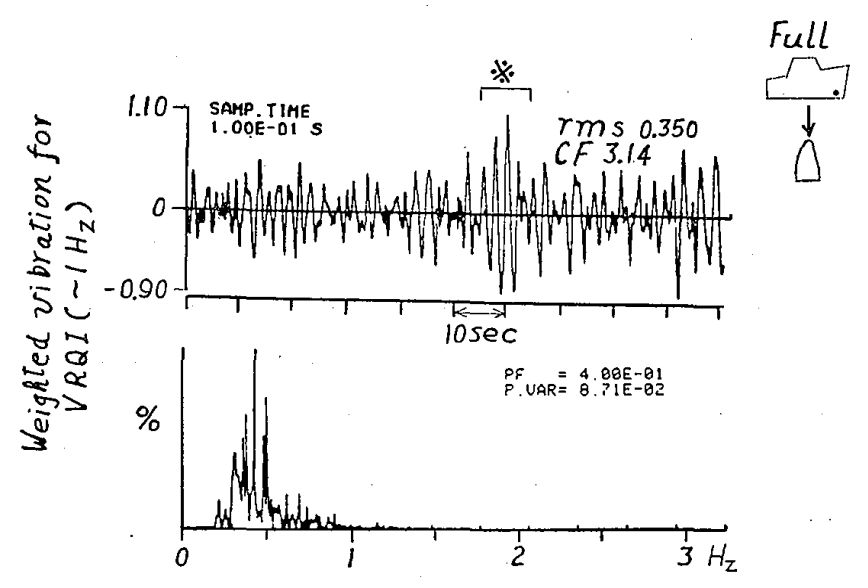

Fig. 6 Examle of analysis of acceleration waves passing weighting network for VRQI $(\sim$ $1 \mathrm{~Hz}$ )
Since the vibration in high frequency component is

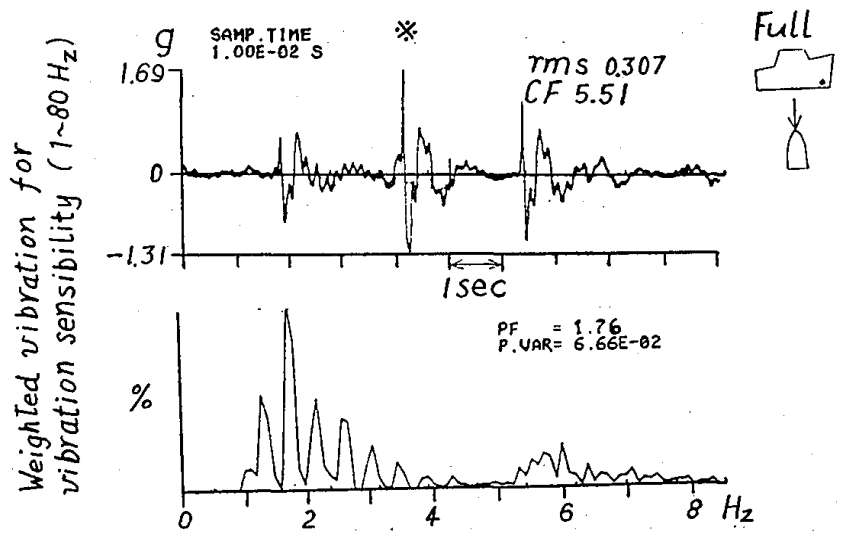

Fig. 7 Example of analysis of acceleration wave passing weighting network for equivalent sensibility 
omitted by the network, the peak value of Fig. 6 reduces to about one-third that of Fig. 5. The lower part of Fig. 6 shows the power spectrum. Frequency component falls in the low frequency zone centering between $0.4 \mathrm{~Hz}$ to $0.5 \mathrm{~Hz}$ and VRQI $(\sim 1 \mathrm{~Hz})$ is 0.35 , which expresses "severe" in the categories of the evaluation criterion.

Fig. 7 shows an example of analysis of acceleration waves passing the weighting network for equivalent sensibility. The peak value during the sweeping period of 10 sec. centering the position marked with $\%$ is $1.69 \mathrm{~g}$, which means the vibration is of considerable strong shock sensibility.

$\mathrm{VL}$ is $110 \mathrm{~dB}$ as converted from rms value of $0.307 \mathrm{~g}$ in $\mathrm{dB}$ unit, which is significantly large. Being double the rms value, VRQI $(1 \sim 80 \mathrm{~Hz})$ is 0.614 , which exeeds the limit of "severe". However, inspite of being often used the rms value due to a good correspondence of its integrated value of stimulus with human response, the rms value is considered unsuitable for evaluation of impulsive vibration. Consequently, together with the reason described in clause 2.3 , it is advisable to use the rms value for the analyzing period of $100 \mathrm{sec}$. in evaluating ride quality. The rms value for whole period was obtained as $0.16 \mathrm{~g}$ by analyzing 10 times successively with sweeping period of 10 sec. Therefore, VL was $102 \mathrm{~dB}$ and VRQI $(1 \sim 80 \mathrm{~Hz})$ was 0.32 , which is corresponding to "severe". In Fig. 7 the crest factor is 5.5, which will be discussed later with the crest factor stipulated in the proposed amendment ${ }^{(6)}$ to ISO 2631. The power spectrum shows that the vibration includes the vibration component centering at $6 \mathrm{~Hz}$ in addition to main component with its center at the peak frequency of $1.76 \mathrm{~Hz}$.

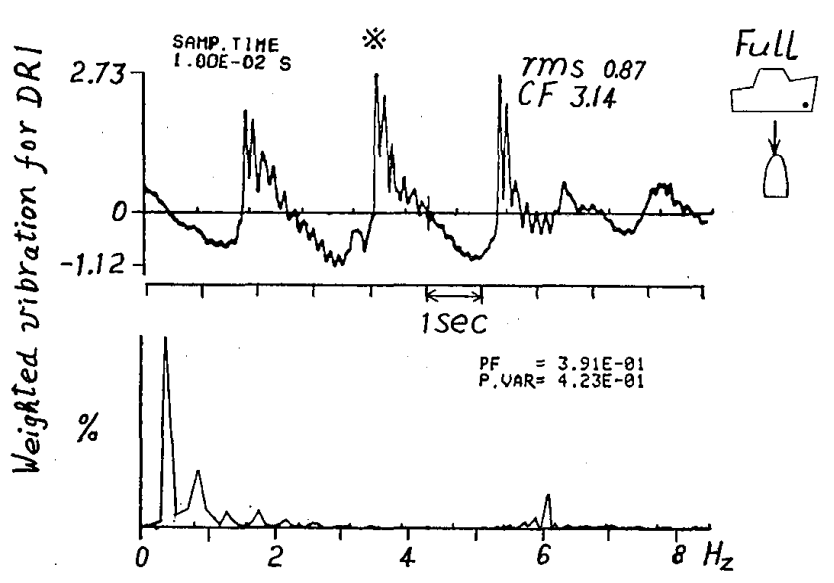

Fig. 8 Example of analysis of acceleration wave passing weighting network for DRI
Fig. 8 shows an exmple of analysis of acceleration waves passing the weighting network for DRI. The peak value of DRI during the sweeping period of $10 \mathrm{sec}$. centering at the position marked with $\%$ is 2 .73. The wave consists of wave groups energized between $0.3 \mathrm{~Hz} \sim 1 \mathrm{~Hz}$ and in the vicinity of $6 \mathrm{~Hz}$, with the peak frequency of 0.391 $\mathrm{Hz}$. The figure 2.73 of DRI is the peak value of the period under the most severe condition during the analyzing period of $100 \mathrm{sec}$.

In summary of aforementioned examples in terms of the most severe condition, the value of VRQI $(\sim 1 \mathrm{~Hz})$, VRQI $(1 \sim 80 \mathrm{~Hz})$, VL, the peak value of ESA and DRI was $0.35,0.32,102 \mathrm{~dB}, 1.69 \mathrm{~g}$ and 2.73 respectively under evaluation during the analyzing period of $100 \mathrm{sec}$. Each of these values clearly proves that the condition is very severe from the viewpoint of human response.

In the next place, an example of analysis for after part of accommodation (amidships) adjacent to engine room under the condition of half speed and head sea will be introduced for ease of understanding.

Fig. 9(a) gives the acceleration waves in frequency range from 1 to $80 \mathrm{~Hz}$ obtained during sampling time of 0.01 sec. In Fig. 9 (b) are given the acceleration waves passing the weighting network for equivalent sensibility. Since the measuring point is in a space adjacent to engine room, the wave patterns in Fig. 9 contain mainly vibrations in high frequency. The wave patterns, however, become clear after passing the weighting network.

The peak value of ESA is $0.129 \mathrm{~g}$ and the vibration level during the sweeping period of 10 sec. is $89 \mathrm{~dB}$, which is obtained by conversion of rms value of $0.028 \mathrm{~g}$ to $\mathrm{dB}$ unit. The VRQI $(1 \sim 80 \mathrm{~Hz})$, 
(a) No weighted vibration

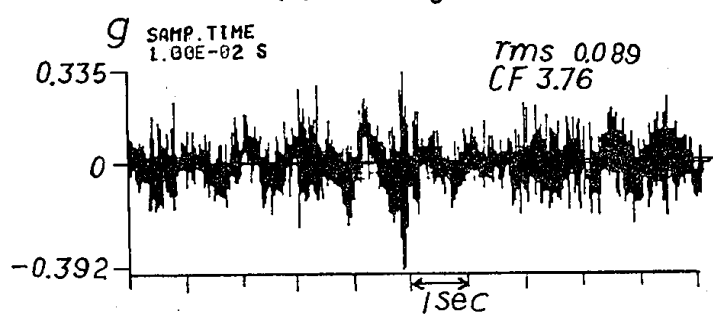

(b) Weighted vibration

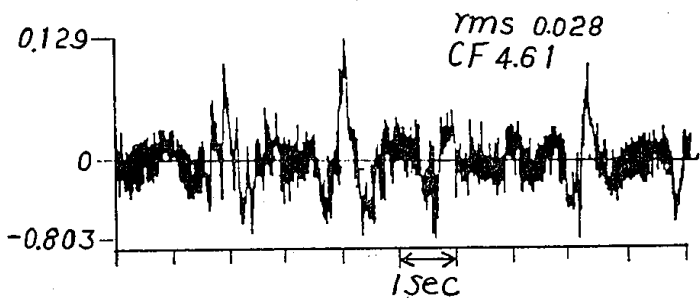

Fig. 9 Examples of analysis of acceleration waves passing or no passing weighting network for equivalent sensibility

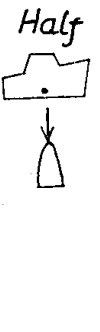

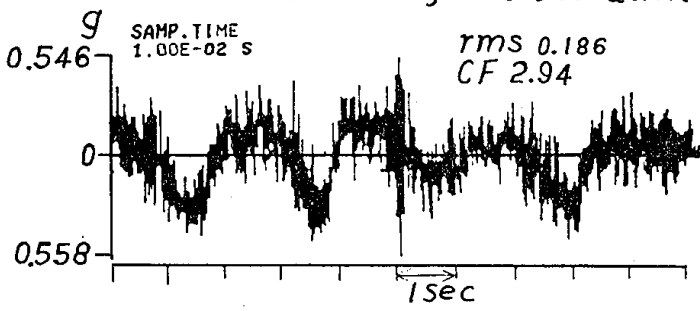

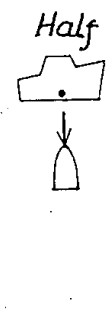

(b) Weighted vibration

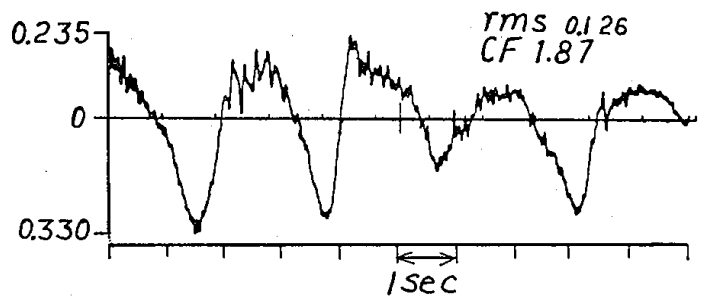

Fig. 10 Examples of analysis of acceleration waves passing or no passing weighting network for DRI

being double rms value, is 0.056 . As the result of analysis carried out successively 10 times, the evaluation values of VL and VRQI $(1 \sim 80 \mathrm{~Hz})$ for analyzing period of $100 \mathrm{sec}$. was $88 \mathrm{~dB}$ and 0.048 respectively.

Fig. 10 (a) gives the acceleration waves obtained for sampling time of 0.01 sec., which represents the actual acceleration as registered on the data-recorder. Fig. 10(b) shows the result of analysis of acceleration waves passing the weighting network for DRI. It is found from (a) that the condition contains mainly vibrations in high frequencies and the wave patterns becomes district in (b). DRI is as small as 0.235 , which means the vibration has no effect upon occurrence of spinal injury.

In summary of aforementioned results evaluated under the condition of half speed, head sea and measuring point at after portion of accommodation adjacent to engine room together with VRQI $(\sim 1$ $\mathrm{Hz})$, each evaluation value for analyzing period of 100 sec. is as follows. VRQI $(\sim 1 \mathrm{~Hz}), \mathrm{VQRI}$ $(1 \sim 80 \mathrm{~Hz})$, VL, peak value of ESA and peak value of DRI was $0.114,0.048,88 \mathrm{~dB}, 0.129 \mathrm{~g}$ and 0. 235 respectivelv. While these evaluation values exceed the "tolerable". limit in long term exposure for the vibration in frequencies below $1 \mathrm{~Hz}$, being component of ship oscillation, vibrations in frequencies more than $1 \mathrm{~Hz}$ proved lesser problem due to less occurrence of impulsive vibration.

Finally, the crest factor will be explained by an example.

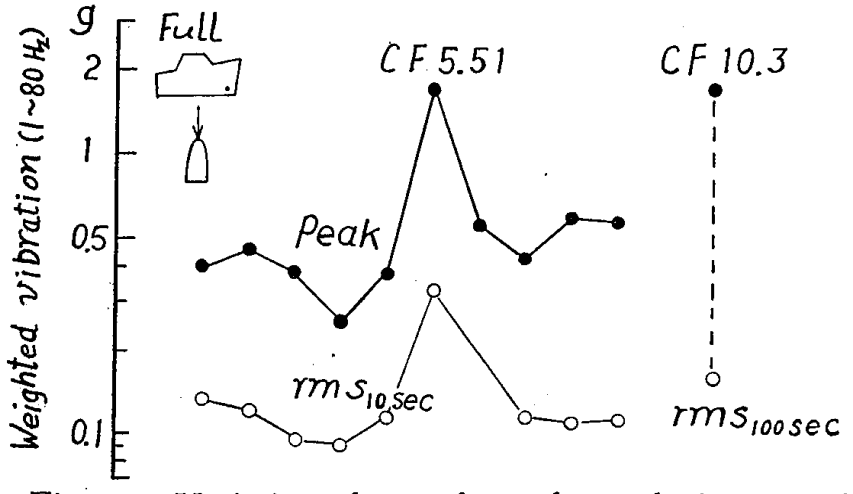

Fig. 11 Variation of crest factor for analyzing period of $100 \mathrm{sec}$ or $10 \mathrm{sec}$
Fig. 11 shows the crest factor for analyzing period of $100 \mathrm{sec}$. including the example of analysis of acceleration waves shown in Fig. 7. The crest factor during $100 \mathrm{sec}$. is obtained by following procedure. First, the peak value and rms value obtained by ten (10) successive analyzing attempts with sweeping period of $10 \mathrm{sec}$. Second, calculate approximately the $\mathrm{rms}$ value ( $\mathrm{rms} 100$ sec.) ${ }^{(*)}$ for $100 \mathrm{sec}$. Then the crest factor for 100 sec. can be obtained by dividing the maximum peak value during $100 \mathrm{sec}$. by the rms value for $100 \mathrm{sec}$. 


$$
\text { (*) } \mathrm{rms} 100 \mathrm{sec} . \risingdotseq \sqrt{\frac{1}{10} \sum_{1}^{10} \mathrm{rms}_{i}^{2}}
$$

where, $\mathrm{rms}_{i}$ is the value for the sweeping period of $10 \mathrm{sec}$.

From Fig. 11 it is noticed that the crest factor for the analyzing period of 100 sec. is 10.3 , while the crest factor for $10 \mathrm{sec}$. including the maximum peak value is 5.51 . This proves that probability to get the maximum value is very small when analyzing period is short, and that, since the rms values for the sweeping period of $10 \mathrm{sec}$. vary together with variation of the peak value during $100 \mathrm{sec}$, difference in crest factors for each $10 \mathrm{sec}$. will be small. In consequence, the claim in the draft amendment to ISO 2631 to increase the analizing period to more than one minute is considered reasonable.

\section{Conclusion}

The typical impulsive vibration of a high speed ship (65 gross tons, 25 knots) was registered on the data-recorder and was analyzed by the real time digital analyzing system. As the result, vibration ride quality index, vibration sensibility magnitude and dynamic response index on spinal injury were obtained and many-sided evaluation method on the basis of human tolerance was presented. This method is featured by employing the weighting network composed of frequency characteristics of human response to shock and vibration.

Under the most severe condition of full speed, head sea and measuring in foreward accommodation, VRQI $(\sim 1 \mathrm{~Hz})$, VRQI $(1 \sim 80 \mathrm{~Hz})$, VL, the peak value of equivalent sensibility acceleration and the peak value of $\mathrm{DRr}$ evaluated for analyzing period of $100 \mathrm{sec}$. was $0.35,0.32,102 \mathrm{~dB}, 1.69 \mathrm{~g}$ and 2. 73 respectively. These value indicated especially very severe condition from the viewpoint of human response. In contrast to the above, under the condition of half speed, head sea and measuring in midship accommodation, evaluation values proved lesser problem due to less frequent occurrence of impulsive vibration except the vibration ride quality in frequency below $1 \mathrm{~Hz}$ exceeded the limit of 0.1 in long term exposure. Results of the study testifies that this method is excellent for evaluation of repeated shocks and vibrations based on human tolerance.

\section{* Appendix}

Dynamic models of human body for VRQI and DRI

Dynamic models proposed by P. R. Payne and his cooperators are shown in Fig. 12 and Table 1.

(4)

(3)

(2)

(1)

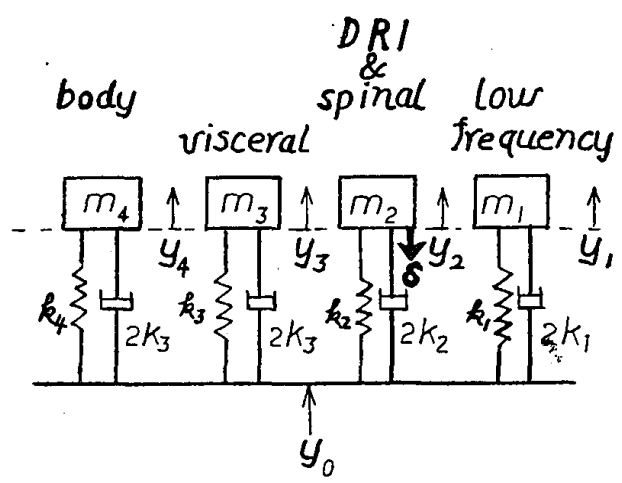

Note :

$$
\begin{aligned}
& 2 \mathrm{k} ; \text { viscous damping constant } \\
& 2 \bar{c} \omega_{n}=2 \mathrm{k} / \mathrm{m} \\
& \omega_{n}=\sqrt{\frac{k}{m}}
\end{aligned}
$$

Fig. 12 Dynamic models of human body for VRQI and DRl
Table 1 Dynamic model coefficients

\begin{tabular}{l|l|ll}
\multicolumn{1}{c|}{ Model } & \multicolumn{1}{c|}{$\overline{\mathrm{c}}$} & \multicolumn{2}{|c}{$\omega_{n} \mathrm{rad} / \mathrm{sec}(\mathrm{Hz})$} \\
\hline low frequency & 1.0 & 1.571 & $(0.25)$ \\
spinal & 0.224 & 52.9 & $(8.4)$ \\
visceral & 0.40 & 25.1 & $(4)$ \\
body & 1.0 & 52.9 & $(8.4)$ \\
\hline
\end{tabular}

VRQI is cxpressed as follows :

$$
\mathrm{VRQI}=\frac{\ddot{\mathrm{y}}_{n}}{\mathrm{~g}}(\mathrm{rms})
$$

where, $\ddot{\mathrm{y}}_{n}$ (rms) is the maximum value among $\ddot{\mathrm{y}}_{1}$, $\ddot{\mathrm{y}}_{2}, \ddot{\mathrm{y}}_{3}$, and $\ddot{\mathrm{y}}_{4}$ obtained from four models of low frequency, spinal, viscerals and body. $\mathrm{g}$ is acceleration of gravity.

DRI is expressed by following equation in a spinal model. 


$$
\begin{gathered}
\frac{\mathrm{d}^{2} \delta}{\mathrm{d} \bar{t}^{2}}+2 \overline{\mathrm{c}} \omega_{n} \frac{\mathrm{d} \delta}{\mathrm{dt}}+\omega_{n}^{2} \delta \frac{\mathrm{d}^{2} \mathrm{y}}{\mathrm{dt}^{2}} \\
\mathrm{DRI}=\frac{\omega_{n}^{2} \delta \max }{\mathrm{g}}
\end{gathered}
$$

Where, $\overline{\mathrm{c}}=0.224, \omega_{n}=52.9 \mathrm{rad} / \mathrm{sec}$

$\delta$ is displacement of mass $m_{2}$ taking positive in direction of gravity.

\section{REFERENCE}

(1) Allen, G. R. ; Progress on a Specification for Human Tolerance of Repeated Shocks, ISO/TC108/SC4, N47, Aug. 1976.

(2) Payne, P. R.; On Quantizing Ride Comfort and Allowable Accelerations, ISO/TC108/SC4, N48, Aug. 1976.

(3) ISO/TC108 (ISO-2631); Guide for the Evaluation of Human Exposure to Whole-Body Vibration, $1 \sim 15,1974$.

(4) Kanda, H. ; Studies on the Evaluation of Human Sensibility on Ship Vibration-II, Japan Institute of Navigation, Vol. 51, 77 83, 1972 (in Japanese).

(5) U. S. Air Force ; "Seat System: Upward Ejection, Aircraft, General Specification for". MIL-S-9479A, USAF June 1967.

(6) SC4-Secretariat (DIN) ; Amendments to ISO 2631, ISO/TC108/SC4, N66, Sep. 1978. 